\title{
Profile of three Brazilian birth cohort studies in Ribeirão Preto, SP and São Luís, MA
}

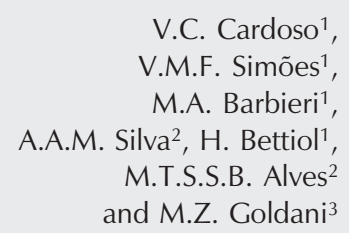

V.C. Cardoso ${ }^{1}$,

V.M.F. Simões ${ }^{1}$,

M.A. Barbieri ${ }^{1}$,

A.A.M. Silva ${ }^{2}$, H. Bettiol ${ }^{1}$,

M.T.S.S.B. Alves ${ }^{2}$

and M.Z. Goldani ${ }^{3}$

\author{
${ }^{1}$ Departamento de Puericultura e Pediatria, Faculdade de Medicina de Ribeirão Preto, \\ Universidade de São Paulo, Ribeirão Preto, SP, Brasil \\ ${ }^{2}$ Departamento de Saúde Pública, Universidade Federal do Maranhão, São Luís, MA, \\ Brasil \\ ${ }^{3}$ Departamento de Pediatria e Puericultura, Faculdade de Medicina, \\ Universidade do Rio Grande do Sul, Porto Alegre, RS, Brasil
}

\section{Correspondence \\ V.C. Cardoso \\ Departamento de Puericultura \\ e Pediatria, FMRP, USP \\ Avenida Bandeirantes, 3900 \\ 14049-900 Ribeirão Preto, SP \\ Brasil \\ Fax: +55-16-3602-2700 \\ E-mail: vicuca@fmrp.usp.br \\ Research supported by FAPESP (Nos. 93/0525-0, 97/09517-1 and 00/09508-7), CNPq (Nos. 523474/96-2 and 520664/98-1), and Fundação de Auxílio ao Ensino, Pesquisa e Assistência do HC, FMRP, USP.}

Received August 30, 2006 Accepted May 29, 2007

\begin{abstract}
We describe three birth cohort studies, respectively carried out in 1978/79 and 1994 in Ribeirão Preto, a city located in the most developed region of Brazil, and in 1997/98 in São Luís, a city located in a less developed region. The objective of the present report was to describe the methods used in these three studies, presenting their history, methodological design, objectives, developments, and difficulties faced along 28 years of research. The first Ribeirão Preto study, initially perinatal, later encompassed questions regarding the repercussions of intrauterine development on future growth and chronic adult diseases. The subjects were evaluated at birth $(\mathrm{N}=6827)$, at school age $(\mathrm{N}=2861)$, at the time of recruitment for military service $(\mathrm{N}=2048)$, and at $23 / 25$ years of age $(\mathrm{N}=2063)$. The study of the second cohort, which started in $1994(\mathrm{~N}=2846)$, permitted comparison of aspects of perinatal health between the two groups in the same region, such as birth weight, mortality and health care use. In 1997/98, a new birth cohort study was started in São Luís ( $N=2443)$, capital of the State of Maranhão. The 1994 Ribeirão Preto cohort and the São Luís cohort are in the second phase of joint follow-up. These studies permit comparative temporal analyses in the same place (Ribeirão Preto 1978/79 and 1994) and comparisons of two contrasting populations regarding cultural, economic and sociodemographic conditions (Ribeirão Preto and São Luís).
\end{abstract}

\section{Introduction}

Cohort studies are considered to be very important, at a time when the relevance of the life cycle for the development of chronic diseases of adults has been recognized. Most of what is known about the etiology of non-
Key words

- Cohort study

- Epidemiological methods

- Public health

- Perinatal health

- Sociodemographic

conditions communicable diseases is limited to risk factors that can be measured and that operate during adult life (1). Thus, longitudinal studies can be the key to the understanding of effects of intrauterine life and childhood conditions on adult diseases (2).

On this basis, working with the fetal ori- 
gin of adult diseases has stimulated investigators to conduct more extensive surveys in the search for explanations of the possible effects of factors operating throughout the life cycle, and even from generation to generation, on adult health (1). Many investigators have organized birth cohorts in order to study health over the life course, but many years will pass before these cohorts will be mature enough to permit the exploration of effects of early health predictors on adult life (2). Consequently, identifying longitudinal studies started several decades back and reporting data collected prospectively about life conditions in infancy is of great interest. Each study permits to point out which living conditions during infancy may affect adult health within a reasonable period of time (2).

In Brazil, the first prospective longitudinal perinatal study of the birth cohort type was conducted in Ribeirão Preto, in 1978/ 79. The project, initially called "Epidemiological-social study of parameters of motherchild health", from which the project called "Perinatal Health in Ribeirão Preto, SP, Brazil" originated, was based on the need to carry out an epidemiological investigation to explore the socioeconomic influences on perinatal health, human reproduction, infant mortality, and medical care, using as much as possible the framework of social epidemiology $(3,4)$.

Questions related to the repercussions of intrauterine development on future growth were later incorporated into the study. With the observation of the existence of a broad articulation between biological determinants of growth along time within a varied social context, it became clear that it would be necessary to have detailed information about the growth pattern of the individuals belonging to the newborn cohort of 1978/1979 (5). Thus, the study, which was originally of the cross-sectional type, was transformed into a prospective longitudinal study of the cohort type, with the cohort having been studied thus far during four different periods: at birth, at school age, at recruitment for military service, and at 23/25 years of age (Table 1).

In 1994, 15 years after the first study, a new cohort was started in Ribeirão Preto (6), a fact that permitted comparison of two groups within the same region and within a given time interval. This study, which is already in the second phase of investigation, performed at school age, used a methodology similar to that employed in the 1978/79 study, permitting a comparison of the various outcomes with those of the previous study (7-10).

Because of the need to evaluate the same outcomes in a distinct socioeconomic context, in 1997/98 the same research group started a new prospective longitudinal study of the birth cohort type in São Luís, the capital of the State of Maranhão, one of the Brazilian states with the lowest Human Development Index (11). This third cohort is being currently evaluated at school age.

The objective of the present report was to describe the methodology used in the three cohort studies conducted in these two Brazilian cities, presenting their history, methodological design, objectives, developments, and difficulties faced along the 28 years of research. This is the opening article of the present issue, which includes papers resulting from the investigations performed using data from these three birth cohort studies.

\section{Patients and Methods}

\section{Methods}

The studies were conducted in two Brazilian cities with different socioeconomic backgrounds. Ribeirão Preto, a city located $320 \mathrm{~km}$ northeast of the capital of the State of São Paulo in the Southeast region of Brazil, a rich and industrialized region, had a Human-Municipal Development index of 0.822 in 1991 and of 0.855 in 2000, occupy- 
ing in 2000 the 6th place in the São Paulo State ranking, considering the 645 municipalities in the State, and the 22nd place in the national ranking, taking into account the 5561 municipalities in the country (11).

São Luís is the capital of the State of Maranhão, located in the Northeast, one of the poorest regions in the country. The city had a Human-Municipal Development index of 0.721 in 1991 and of 0.778 in 2000, when it occupied the 1st place in the Maranhão State ranking and the 1112th place in the national ranking (11).

\section{The first Ribeirão Preto cohort (1978/79)}

In 1978, Ribeirão Preto had 318,496 inhabitants. Of these, $96.8 \%$ resided in the urban area (12). The economically active population corresponded to $42.7 \%$ of the total population and the main economic activities of the city were services, commerce and the sugar cane industry, with the last one being the most important in the country (13). Regarding schooling, $86.1 \%$ of the population started to learn reading and writing in the 5th year of life. Most Ribeirão Preto births occurred in hospitals (14) and therefore only hospital births were studied.

The information for the study was obtained from 9067 interviews held with the mothers immediately after delivery, corresponding to $98 \%$ of the liveborn infants delivered at the eight maternity hospitals of Ribeirão Preto over a period of 1 year. The proportion of mothers discharged from hospital before they could be interviewed was $2.5 \%$ and less than $1 \%$ refused to be interviewed (9). Infants born to mothers who did not reside in the municipality $(\mathrm{N}=2173)$ and twins $(\mathrm{N}=146)$ were excluded from the study. Thus, the study population comprised all infants born in hospitals to mothers residing in Ribeirão Preto, for a total of 6748 singletons representing approximately $91 \%$ of the total number of liveborn infants in 1979 which, according to the IBGE, was
7437 (15). The main objectives of the study were to examine the sociodemographic characteristics of the population and the medical care offered during pregnancy and delivery, to estimate the low birth weight and the infant mortality rates, as well as the relation of socioeconomic, demographic and reproductive factors and social class to perinatal indicators and to the health services utilization (3,16-18).

Questionnaires were used to obtain demographic data (parental age, origin, newborn gender), socioeconomic data of the parents (schooling, occupation), pregnancy and delivery data including medical care (date of the last menstruation to calculate duration of gestation, maternal smoking during pregnancy, type of medical assistance for prenatal care, and delivery, parity, type of delivery, date of birth) and data regarding the newborns (birth weight and length) and the occurrence of infant death $(3,16)$. When the mother was not interviewed, data were collected from the medical records. Birth weight and length were measured by trained personnel with appropriate devices, donated by the research team to all hospitals. The babies were weighed naked on weekly calibrated scales with $10-\mathrm{g}$ precision. Two trained staff members measured length at birth with the baby lying in the supine position on a neonatometer with a fixed vertical headpiece and a smooth sliding vertical footpiece. Measurements were taken to the nearest $0.5 \mathrm{~cm}$. The same variables were used and analyzed in the subsequent studies. The methodology of this first cohort phase has been detailed in previous publications $(3,16)$.

In the second follow-up of this cohort in $1987 / 89$, the individuals were evaluated in school (5), the place that offered the highest probability of locating the largest possible number of children in view of the high rate of access to school in Ribeirão Preto and the low emigration rate of less than $1 \%$ (19).

The main objective of this second follow-up was the assessment of health indica- 
tors in school age children as a function of social and biological birth conditions, with an analysis of growth and development aspects. The intention was to collect information about $50 \%$ of the individuals of the $1978 / 79$ cohort. Of the schoolchildren located through the enrollment charts for 1st to 4th grade of elementary school, 2861 belonged to the initial cohort (43.5\%), after the exclusion of deaths up to the 1st year of life (257), absentees, and dropouts. The children with the lowest birth weights, whose mothers had low schooling, had no companion, were multiparous, or smoked during pregnancy had lower follow-up rates (20). The data were recorded on specially prepared forms, one per school grade, containing the full name, sex, address, mother's name, and date and hospital of birth for each student. These data were then transcribed to individual charts. On a previously scheduled day, the team returned to the school to collect the anthropometric data of the children.

The following data were obtained by interviewing the mothers: name, marital status, occupation, schooling, smoking habit, number of children, obstetrical history, occupation of household head, family income, and child's schooling, in addition to other data already collected from the child's enrollment form (name, date of birth, hospital of birth, school, grade, weight, height, and head circumference).

The third follow-up of the cohort study, involving the individuals at 18 years of age, occurred in 1996/1997. In this third stage, the authors assessed the effect of some biological and social variables at birth and at 18 years on the risk of short stature, on the body mass index, and on the prevalence of obesity. Compulsory military service was used to locate the individuals, even though this meant that only males would be studied. This was mainly due to the fact that the Military Board stated that $70 \%$ of the individuals responded to the call for enlistment. The population assessed in this stage of the study was defined as all conscripts born as singletons by hospital delivery in Ribeirão Preto from June 1, 1978 to May 31, 1979. A total of 2083 individuals whose birth charts were identified in the files of the first phase of the study were located in the Military Service Board of Ribeirão Preto. Of these 2083 young men, 35 were excluded for being twins, with the final sample thus consisting of 2048 individuals (61.3\% of the original sample of boys). Follow-up rates were higher for those who had higher birth length, were born into higher social class families, and were from higher schooling, older, cohabiting, and non-smoking mothers (13).

Data about the youths were obtained by an interview. The objective was to define their social status by means of the following parental data: names of the parents and occupation and schooling of the household head. The following information was obtained about the individuals in the sample: anthropometric data, name, address, birth date, hospital of birth, type of school, schooling, grade he attended or concluded before leaving school, smoking habit, age at first job, monthly earnings, type of medical care, whether he still lived with his parents, and number of household persons.

The fourth follow-up of the cohort study was started in 2002, when the individuals were 23-25 years old. On that occasion, Ribeirão Preto had 543,885 inhabitants and an urbanization rate of $99.6 \%$ (19). For this reason, the search was carried out only in the urban area. In this new search, 79 individuals who had been erroneously registered as not residing in Ribeirão Preto were added to the database, with a consequent correction of the initial sample from 6748 to 6827 individuals. A total of 5665 individuals were located by a search of the Hygia system of electronic scheduling of visits for users of the medical services of SUS (the Portuguese acronym for Unified Health System), of the lists of users of private health plans, of the charts for evaluation of schoolchildren of 
the cohort obtained in 1987/89 (5), and of the chart for evaluation of the conscripts belonging to the original cohort (13). A total of 2063 young adults effectively participated, corresponding to $31.8 \%$ of the cohort ( $\mathrm{N}=6484)$ after exclusion of 343 deaths up to 20 years. Follow-up rates were higher for women, those born preterm, those from families with more qualified occupations, and those whose mothers were married, did not smoke during pregnancy and had five or more years of schooling. Detailed information about the methodology used can be obtained from a previous specific publication (21).

The objective of the fourth phase of the study was to assess the association between intrauterine malnutrition and antecedents of non-communicable chronic diseases of adults, as well as the association between birth variables and height and body mass index at school age and in young adults, in addition to the effect of some intervening factors such as smoking habit, sedentary life style, and alcohol and drug consumption on the associations under study $(21,22)$.

The data obtained in each follow-up phase were linked to the birth archives regarding the variables hospital of birth and order number. The current database for the 1978/79 cohort comprises 822 variables, all of which were submitted to consistency tests during data entry.

The study population, the size and representativeness of the sample and the site of data collection during the different phases of the study are described in Table 1, and the objectives of the cohort are presented in Table 2 .

\section{The second Ribeirão Preto cohort (1994)}

In 1994, the population of Ribeirão Preto was 461,427 inhabitants, with a $44.9 \%$ increase compared to $1978 / 79$ (23). A new longitudinal study of the cohort type was then started, basically using the same meth- odological design. The objective of this phase was to study again the sociodemographic characteristics of the population and the medical care offered during pregnancy and delivery, and to estimate the rates of low birth weight, preterm birth, intrauterine growth restriction, and infant mortality, which permitted historical comparisons with the maternal-fetal health indicators observed in the previous study $(6,9,10)$.

Data regarding a sample of liveborn infants delivered at hospitals were collected using a standard questionnaire applied in interviews with the mothers. The following information was obtained: anthropometric data regarding the newborn infants (weight and length), gestational age and data from the registration forms and medical records of the hospitals, as well as information regarding death certificates for children included in the project who died during the first year of life.

The initial prevision of the number of births for 1994 was 11,650 infants (including twin births and infants not residing in Ribeirão Preto) according to the information of the Hospital Data Processing Center (CPHD in the Portuguese acronym) of the University Hospital, Faculty of Medicine of Ribeirão Preto, University of São Paulo, which collects and records all the hospital admission data for all hospitals in the municipality, including deliveries. The authors opted for the collection of data regarding all live births that had occurred over 4 consecutive months, representing one third of the births for the year, since there was no seasonality for the important variables collected in the 1978/79 study, such as low birth weight, preterm birth, maternal age, and others. Thus, the estimated number of infants was 3850 .

For the comparison and validation of the project sample, the births that had occurred in all hospitals were monitored at the $\mathrm{Mu}$ nicipal Health Secretariat by means of the Information System Regarding Live Births (SINASC in the Portuguese acronym). A 
total of 10,963 births were observed at the end of 1994, corresponding to a sample size of 3654 individuals over a four-month period. Data regarding 3663 newborn infants were recorded but, after removal of 733 children not residing in Ribeirão Preto and of 84 twin births, the sample size of this cohort was reduced to 2846 individuals (6). The interview was held after delivery, with the mother conscious and in good physical condition, after she had given oral consent. When discharge from the hospital occurred before the interview, the mother was inter- viewed at home when possible. Less than $1 \%$ of the mothers refused to be interviewed and $3.2 \%$ were discharged from the hospital before the interview.

The anthropometric measurements were made in the same way as described in the previous study, and the variables collected were practically the same. The description of the study population, the size and representativeness of the sample and the site of data collection are presented in Table 1 . The objectives of the cohort study are listed in Table 2.

Table 1. Chronology of the three cohort studies: Ribeirão Preto 1978/79, Ribeirão Preto 1994 and São Luís 1997/98.

\begin{tabular}{|c|c|c|c|c|}
\hline Cohort & Year of study & Description of the study populations & Sample & $\begin{array}{l}\text { Representativeness of the sample and data } \\
\text { collection }\end{array}$ \\
\hline \multirow[t]{4}{*}{ Ribeirão Preto $1978 / 79$} & $1978 / 79$ & $\begin{array}{l}\text { Liveborn singletons delivered in } \\
\text { Ribeirão Preto from June 1, } 1978 \text { to } \\
\text { May } 31,1979\end{array}$ & $6827^{\star}$ & $\begin{array}{l}98 \% \text { of the universe of liveborn singletons } \\
\text { delivered at the eight public and private } \\
\text { maternity hospitals of Ribeirão Preto over a } \\
\text { period of one year and residing in the town. }\end{array}$ \\
\hline & $1987 / 89$ & $\begin{array}{l}\text { Children enrolled in } 1 \text { st to } 4 \text { th grades } \\
\text { of elementary school born in Ribeirão } \\
\text { Preto from June 1, } 1978 \text { to May 31, } 1979\end{array}$ & 2861 & $\begin{array}{l}43.5 \% \text { of the original cohort; } \\
76 \text { state, city and private elementary } \\
\text { schools. }\end{array}$ \\
\hline & $1996 / 97$ & $\begin{array}{l}\text { Conscripts born by hospital delivery in } \\
\text { Ribeirão Preto from June } 1,1978 \text { to } \\
\text { May 31, } 1979\end{array}$ & 2048 & $\begin{array}{l}61.3 \% \text { of the males in the cohort; } \\
\text { Military Service Board of Ribeirão Preto. }\end{array}$ \\
\hline & $2002 / 04$ & $\begin{array}{l}30 \% \text { of } 1978 / 79 \text { cohort at } 23 / 25 \\
\text { years of age }\end{array}$ & 2063 & $\begin{array}{l}31.8 \% \text { of the original sample - living } \\
\text { individuals at } 20 \text { years of age (6484); } \\
\text { Electronic visit scheduling system of the } \\
\text { Unified Health System (SUS); } \\
\text { Lists of users of private health plans; } \\
\text { Evaluation chart of schoolchildren of the } \\
1987 / 89 \text { cohort; } \\
\text { Evaluation chart of conscripts belonging } \\
\text { to the original cohort. }\end{array}$ \\
\hline \multirow[t]{2}{*}{ Ribeirão Preto 1994} & 1994 & $\begin{array}{l}\text { Liveborn singletons residing in Ribeirão } \\
\text { Preto born over } 4 \text { consecutive months } \\
\text { from April } 25 \text { to August 25, } 1994\end{array}$ & 2846 & $\begin{array}{l}1 / 3 \text { of the births in the year; } \\
\text { Ten public and private maternity hospitals. }\end{array}$ \\
\hline & $2004 / 05$ & Cohort individuals at $9 / 10$ years of age & 915 & $\begin{array}{l}32.1 \% \text { of the initial cohort; } \\
\text { Public and private schools. }\end{array}$ \\
\hline \multirow[t]{2}{*}{ São Luís 1997/98 } & $1997 / 98$ & $\begin{array}{l}\text { Liveborn singletons delivered in hospitals } \\
\text { and residing in São Luís during the period } \\
\text { from March 1, } 1997 \text { to February 28, } 1998\end{array}$ & 2443 & $\begin{array}{l}96.3 \% \text { of all births; } \\
\text { Ten public and private maternity hospitals. }\end{array}$ \\
\hline & $2005 / 06$ & Individuals of the cohort at $7 / 9$ years of age & 853 & $\begin{array}{l}34.9 \% \text { of the original cohort; } \\
\text { Public and private schools. }\end{array}$ \\
\hline
\end{tabular}

*Seventy-nine individuals who had been recorded as non-residing in Ribeirão Preto in the original cohort, but who were now residing in the town, were incorporated into the 2002/2004 evaluation. 
Table 2. Objectives of the three cohort studies carried out in Ribeirão Preto in 1978/79 and 1994, and in São Luís in 1997/98.

Year of study

1st Cohort Description of the study

1978/79 Perinatal health in Ribeirão Preto, SP, Brazil: liveborn singletons, born from June 1978 to May $1979(N=6827)$.

Objectives

-To describe the sociodemographic characteristics of the population and the medical care offered during pregnancy and delivery.

- To estimate the percentage of pregnancy in adolescence, the low birth weight and the infant mortality rates.

.To determine the association between socioeconomic, demographic, reproductive, and health service factors and the cesarean section rate.

-To determine the association of maternal age, social class and maternal smoking with the low birth weight rate.

. To determine the association of birth weight and social class with infant mortality.

-To describe the medical care for adolescent mothers during pregnancy and at delivery.

Follow-up in $1987 / 89$
Description of the study

-From the maternity hospital to school: evaluation of children attending 1st to 4th grades of elementary school, born from June 1978 to May $1979(\mathrm{~N}=2861)$.

Objectives

-To estimate the prevalence of infant malnutrition and obesity among schoolchildren of the cohort.

- To evaluate weight and height growth according to social class at the time of birth.

- To investigate the association of birth weight and social class with childhood malnutrition and obesity.

. To investigate the association of maternal smoking during pregnancy with body mass index at school age.

-To study the influence of early life factors on body mass index at school age.

Follow-up in

1996/97

Description of the study

.Conscripts born by hospital delivery in Ribeirão Preto from June 1, 1978 to May 31, $1979(N=2048)$.

Objectives

- To study the influence of early life factors on final height.

- To study the influence of early life factors on body mass index during young adult age.

-To investigate the association of maternal smoking during pregnancy with body mass index during young adult age.

-To evaluate the relative strength of birth weight and length in contrast to the social factors as determinants of height at 18 years of age.

Follow-up in $2002 / 2004$

\section{Description of the study}

. From perinatal health to young adult health: study of the cohort born in 1978/79 in RibeirãoPreto hospitals, SP (N = 2063). Objectives

- To determine whether intrauterine growth restriction (IUGR) is associated with the following risk factors for noncommunicable chronic diseases of adults: obesity, sensitization to allergens, alteration of pulmonary function, arterial hypertension, alterations of coagulation factors and of lipoproteins, hyperglycemia, metabolic syndrome, and asthma.

-To determine the effect of some intervening factors such as tobacco smoking, sedentary life style, and alcohol and drug consumption in the association between IUGR and antecedents/chronic diseases of adults.

- To estimate the prevalence of metabolic syndrome in a young adult population.

. To evaluate the effect of social mobility from birth to adult age on adult chronic diseases.

- To describe physical activity patterns and food consumption during young adult age according to socioeconomic and demographic characteristics.

- To estimate cohort mortality and associated factors up to 25 years of age.

- To investigate whether being born with IUGR and being overweight at school age increases body mass index during young adult life.

- To evaluate the agreement between the physical activity level measured with a questionnaire and the self-reported level of physical activity. 
Table 2 continued.

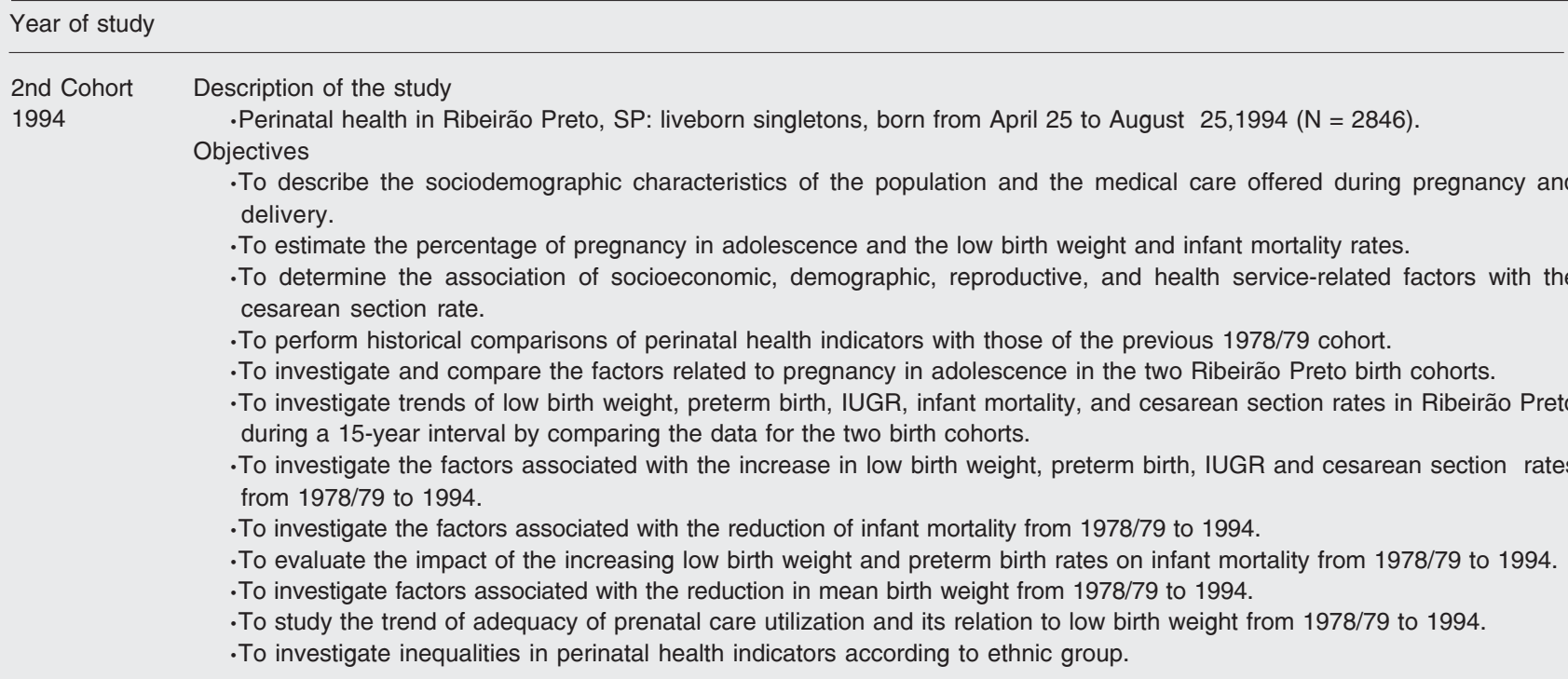

\section{3rd Cohort Description of the study}

1997/98 -Perinatal health and mother and child health care in the municipality of São Luís, MA: liveborn singletons born at hospitals from March 1, 1997 to February 28, 1998 ( $N=2443)$.

Objectives

- To describe the sociodemographic characteristics of the population and the medical care offered during pregnancy and delivery.

-To estimate the percentage of pregnancy in adolescence and the low birth weight and infant mortality rates.

-To determine the association between socioeconomic, demographic, reproductive, and health service factors and the cesarean section rate.

.To investigate the risk factors for low birth weight, especially the association between cesarean section and risk of low birth weight.

- To evaluate the quality of the data of the System of Information about Liveborns (SINASC in the Portuguese acronym) and compare it to the cohort data (gold standard).

-To evaluate the quality of care offered to mother and newborn infant by the Unified Health System (SUS in the Portuguese acronym).

- To evaluate the association of low maternal age with preterm birth.

- To compare the rates of low birth weight, preterm birth, IUGR, and infant mortality with these indicators in the Ribeirão Preto cohort from the same decade, in 1994.

-To investigate factors associated with inadequate prenatal care utilization.

-To study risk factors for preterm birth.

-To investigate the reasons for the low birth weight paradox (a higher rate in the more developed town, Ribeirão Preto, and a lower rate in the less developed town, São Luís).

-To investigate the variation of low birth weight, preterm birth and IUGR according to socioeconomic characteristics in the São Luís and Ribeirão Preto cohorts in the 1990 decade.

- To investigate why the risk of cesarean section is higher in Ribeirão Preto than in São Luís.

- To investigate why the risk of inadequate prenatal care utilization is higher in São Luís than in Ribeirão Preto.

-To investigate why the risk of smoking during pregnancy is higher in Ribeirão Preto than in São Luís.

Follow-up of the 2nd

Ribeirão

Preto cohort, 1994 and of the 3rd cohort, São Luís 1997/98

\section{Description of the study}

-Evaluation of the 1994 Ribeirão Preto cohort at 8/10 years, and of the 1997/98 São Luís cohort at 7/9 years of age.

Objectives

- To investigate the association of birth weight with cognitive function, behavioral and affective problems, arterial blood pressure, childhood depression, pulmonary function, bronchial asthma, allergic rhinitis, and intestinal inflammatory disease at school age.

-To determine whether the effects of the different birth weight groups on the variables studied are modulated by socioeconomic factors, family environment and life style.

- To evaluate the association of birth weight with height, obesity and malnutrition at school age. 
The second phase of this 1994 cohort was started in 2004 and will be described later since it belongs to a joint study with the São Luís cohort.

\section{The 1997/98 São Luís cohort}

The São Luís cohort was studied using the same methodology as used for the two Ribeirão Preto cohorts (1978/79 and 1994) $(3,6,16)$ with the objective of obtaining information about the perinatal health in this municipality, studying the sociodemographic characteristics of the population, the medical care provided during pregnancy and delivery, and estimating the low birth weight, preterm birth, intrauterine growth restriction, and infant mortality rates, for comparison with the 1994 Ribeirão Preto indicators.

The municipality of São Luís is located on the São Luís Island in the North of the State of Maranhão, with an area of $518 \mathrm{~km}^{2}$. Total population in 1998 was 819,639 inhabitants. Delivery care was provided by 18 public and private health units. The sample of hospital births studied represented about $96.3 \%(95 \% \mathrm{CI}=94.1-98.6 \%)$ of all births that occurred in São Luís, guaranteeing the representativeness of the hospital birth sampling (24). The study was conducted at 10 units during the period from March 1, 1997 to February 28, 1998. The study sample consisted of 2542 births in hospitals from mothers residing in São Luís; after exclusion of twins and stillbirths, 2443 singletons were included in the analysis. The variables collected were essentially the same as those for the 1994 Ribeirão Preto cohort. Losses due to refusal or inability to locate the mother occurred in $5.8 \%$ of cases.

The study population, the size and representativeness of the sample and the site of data collection during the different phases of the study are described in Table 1, and the objectives of the cohort are presented in Table 2.
The second phase of the 1994 Ribeirão Preto cohort and of the 1997/98 São Luís cohort

The individuals in the Ribeirão Preto cohort completed 10 years of age in 2004, and those in the São Luís cohort completed 8 years in 2005. For both cohorts, data collection has ended and data entry is ongoing. The objective of this follow-up is to investigate the association between birth weight and cognitive function, behavioral and affective problems, arterial blood pressure, childhood depression, pulmonary function, bronchial asthma, allergic rhinitis, and intestinal inflammatory disease during school age. The remaining objectives of the two followup studies for the cohorts are listed in Table 2.

Five weight groups were considered for the study: very low birth weight (less than $1500 \mathrm{~g})$, low birth weight $(1500 \vdash 2000 \mathrm{~g})$, insufficient birth weight $(2500 \vdash 3000 \mathrm{~g})$, normal birth weight $(3000 \vdash 4250 \mathrm{~g})$, and very high birth weight $(\geq 4250 \mathrm{~g}$, for children with a birth weight at least two standard deviations above the mean for the population).

Information about sociodemographic and maternal factors, pregnancy and delivery and the characteristics of the babies at birth was obtained in a similar manner in Ribeirão Preto and São Luís. The minimum sample size for each follow-up study was 835 children.

To locate the intended Ribeirão Preto sample of schoolchildren enrolled in the 125 elementary schools existing in town, a general student registry managed by the State Education Secretariat was consulted. The full names of the students and of their parents, the date of birth and address, school, grade and study room were obtained. Once an individual belonging to the cohort was identified, the family was contacted.

In São Luís there are 432 elementary schools, 77 of them being city schools, 89 state schools, 75 private, 86 community private, and 105 philanthropic private. Due to 
the lack of a complete registration of the children, a school census of 1st and 2nd grades of elementary school was performed to collect the name of the mother and the name, gender and birth date of the child. The children belonging to the cohort were then identified and the variables in the census list were compared to those in the cohort list. The mother was then invited through the school for an interview. Some children not identified in school were located by an active search starting from the address recorded on the birth questionnaire.

After the reasons for the evaluation were explained, written informed consent was requested for the execution of the various stages of the study (interview, clinical evaluation, evaluation of pulmonary function, and cognitive, affective and behavioral evaluation). Cognitive, affective and behavioral factors were assessed using the following instruments:

Strength and Difficulties Questionnaire: the test provides scores for the following dimensions: emotional symptoms, behavioral problems, hyperactivity, social relationships, and pro-social behavior (25).

Raven's Progressive Matrices Test: a test for cognitive evaluation standardized for São Paulo State children by Angelini (26). The test assesses general intelligence aspects based on Spearman's multifactorial theory (27).

Human Figure Drawing: an evaluation of maturity that takes into account evolutive and emotional indicators present in graphic production. The Human Figure Drawing has been standardized for Brazil by Hutz and Antoniazzi (28).

Children Depression Inventory: a selfreport inventory filled out by the child, elaborated in 1981 by Kovacs (29). The inventory was adapted and standardized by Gouveia et al. (30) in Paraíba and used by Hallak (31) to determine the prevalence of depression among Ribeirão Preto schoolchildren. The Depressive Symptoms Scale for Teachers, Children Depression Inventory version, was also applied.
Height, weight and skinfold thickness measurements were performed using classical standardized techniques (32), and blood pressure was measured with a digital sphygmomanometer (33). The questionnaire of the International Study of Asthma and Allergies in Childhood (ISAAC) was used to evaluate the symptoms of asthma and allergic rhinitis (34). A sub-sample of children was invited to perform the methacholine challenge test. With an estimate of a $20 \%$ asthma prevalence in this age range, about 360 children in each town will participate in this phase of the study. Children with complaints suggestive of allergic rhinitis and/or bronchial asthma were invited to perform skin tests for immediate hypersensitivity to inhalant allergens.

\section{Final considerations}

By describing the methodological history of three cohort studies still underway in two different Brazilian municipalities, the present study intended to understand important health questions within the context of epidemiological transition, taking into account the marked epidemiological differences between the two populations studied $(35,36)$.

The follow-up of two cohort studies separated by a 15 -year interval and the comparison of two Brazilian cities with different socioeconomic realities are pioneering investigations in Brazil and are highly relevant to the understanding of the diversity of the epidemiological situations of the different study populations. In addition, studies of the same cohort analyzed at birth, at school age, at 18 years for men, and during adult age are still rare in Brazil.

The comparative analysis of the three cohort studies, in addition to being obviously important and relevant within the public health context, opens many possibilities for the analysis of the health situation by analyzing different realities at the same time or at different times in studies of morbidity 
and mortality, among others. Another important factor is the unified methodology used in the three studies, with the creation of a large single database that permits a comparative analysis of different realities. The comparison of data for two contrasting populations from the economic and sociodemographic viewpoint (São Luís and Ribeirão
Preto) permitted the authors to answer new questions that cannot be answered by the analysis of a single population, in addition to contributing to the evaluation of social inequalities in perinatal health in Brazil. The results of the cohorts also provide subsidies for the planning of actions and for the elaboration of health policies.

\section{References}

1. Batty GD, Morton SM, Campbell D, Clark H, Smith GD, Hall M, et al. The Aberdeen Children of the 1950's cohort study: background, methods and follow-up information on a new resource for the study of life course and intergenerational influences on health. Paediatr Perinat Epidemiol 2004; 18: 221-239.

2. Osler M, Andersen AM, Lund R, Batty GD, Hougaard CO, Damsgaard MT, et al. Revitalising the Metropolit 1953 Danish male birth cohort: background, aims and design. Paediatr Perinat Epidemiol 2004; 18: 385-394.

3. Barbieri MA, Gomes UA, Barros-Filho AA, Bettiol H, Almeida LE, Silva AA. Saúde perinatal em Ribeirão Preto, SP, Brasil: a questão do método. Cad Saúde Pública 1989; 5: 376-387.

4. Almeida LE, Barbieri MA, Gomes UA, Reis PM, Chiaratti TM, Vasconcellos V, et al. Peso ao nascer, classe social e mortalidade infantil em Ribeirão Preto. Cad Saúde Pública 1992; 8: 404-413.

5. Bettiol H, Barbieri MA, Gomes UA, Gutierrez MR. School children's growth in Ribeirão Preto, Brazil. The Eighth International Congress of Auxology. Philadelphia, June 29-July 2. 1997. p 26-27.

6. Bettiol H, Barbieri MA, Gomes UA, Andrea M, Goldani MZ, Ribeiro ER. Perinatal health: methodology and characteristics of the studied population. Rev Saúde Pública 1998; 32: 18-28.

7. Goldani MZ, Bettiol H, Barbieri MA, Tomkins A. Maternal age, social changes, and pregnancy outcome in Ribeirão Preto, southeast Brazil, in 1978-79 and 1994. Cad Saúde Pública 2000; 16: 1041-1047.

8. Gomes UA, Silva AA, Bettiol H, Barbieri MA. Risk factors for the increasing caesarean section rate in Southeast Brazil: a comparison of two birth cohorts, 1978-1979 and 1994. Int J Epidemiol 1999; 28: 687-694.

9. Silva AA, Barbieri MA, Gomes UA, Bettiol H. Trends in low birth weight: a comparison of two birth cohorts separated by a 15-year interval in Ribeirão Preto, Brazil. Bull World Health Organ 1998; 76 : 73-84.

10. Bettiol H, Rona RJ, Chinn S, Goldani M, Barbieri MA. Factors associated with preterm births in southeast Brazil: a comparison of two birth cohorts born 15 years apart. Paediatr Perinat Epidemiol 2000; 14: 30-38.

11. IDH-M (Índice de Desenvolvimento Humano Municipal 2000). http:// www.frigoletto.com.br/GeoEcon/menuecon.html. Accessed February 22, 2007.

12. IBGE - Fundação Instituto Brasileiro de Geografia e Estatística. Censo demográfico - 1980. Município de Ribeirão Preto. Rio de Janeiro: IBGE; 1980.

13. Haeffner LS, Barbieri MA, Rona RJ, Bettiol H, Silva AA. The relative strength of weight and length at birth in contrast to social factors as determinants of height at 18 years in Brazil. Ann Hum Biol 2002; 29: 627-640.

14. Baruffi L, Martinez AR, Baldochi J. Assistência obstétrica no município de Ribeirão Preto de 1956 a 1962. Matern Infanc 1965: 24: 117-123.

15. IBGE - Fundação Instituto Brasileiro de Geografia e Estatística. Contagem da População: Resultados Relativos a Sexo da População e Situação da Unidade Domiciliar. Rio de Janeiro: IBGE; 1996.

16. Gomes UA, Bettiol H, Silva AAM, Almeida LEA, Barros Filho AA, Barbieri MA. Saúde perinatal em Ribeirão Preto, SP, Brasil: Apresentação de algumas características demógrafo-sociais e da atenção médica da população estudada. Cad Saúde Pública 1990; 6: 7-17.

17. da Silva AA, Barbieri MA, Bettiol H, Dal Bo CM, Mucillo G, Gomes UA. Perinatal health: low birth weight and social class. Rev Saúde Pública 1991; 25: 87-95.

18. Bettiol H, Barbieri MA, Gomes UA, Wen LY, Reis PM, Chiaratti TM, et al. Atenção médica à gestação e ao parto de mães adolescentes. Cad Saúde Pública 1992; 8: 404-413.

19. SEADE (Fundação Sistema Nacional de Análises de Dados). Informações dos Municípios Paulistas (São Paulo em Dados). http:// www.seade.gov. br. Accessed July 19, 2005.

20. Tomé FS, Cardoso VC, Barbieri MA, Silva AAM, Simões VMF, Garcia $\mathrm{CA}$, et al. Are birth weight and maternal smoking during pregnancy associated with malnutrition and excess weight among school age children? Lessons from the past. Braz J Med Biol Res 2007; 40: 1221-1230.

21. Barbieri MA, Bettiol H, Silva AA, Cardoso VC, Simoes VM, Gutierrez MR, et al. Health in early adulthood: the contribution of the 1978/79 Ribeirão Preto birth cohort. Braz J Med Biol Res 2006; 39: 10411055.

22. Barker DJP. Mothers, babies and health in later life. 2nd edn. Edinburgh: Churchill Livingstone; 1998.

23. IBGE. Censo Demográfico 1991: resultados do universo relativos às características da população e dos domicílios. Rio de Janeiro: IBGE; 1994.

24. de Silva AA, Coimbra LC, da Silva RA, Alves MT, Lamy FF, Carvalho $\mathrm{LZ}$, et al. Perinatal health and mother-child health care in the municipality of São Luís, Maranhão State, Brazil. Cad Saúde Pública 2001; 17: 1413-1423.

25. Goodman R. The Strengths and Difficulties Questionnaire. http:// www.sdqinfo.com. Accessed March 13, 2003.

26. Angelini W. Manual das matrizes progressivas coloridas de Raven: 
escala especial. São Paulo: Centro Editor de Testes e Pesquisas em Psicologia; 1999.

27. Spearman $\mathrm{C}$. The nature of intelligence and the principles of cognition. London: Macmillan; 1923.

28. Hutz CS, Antoniazzi AS. O desenvolvimento da figura humana em crianças de 5 a 15 anos de idade: normas para avaliação. Psicol Reflex Crí 1995; 8: 3-18.

29. Kovacs MA. Developmental perspective on methods and measures in the assessment of depressive disorders: The clinical interview. In: Rutter M, Izard C, Read P (Editors), Depression in young people: Developmental and clinical perspectives. New York: Guilford Press; 1983.

30. Gouveia VV, Barbosa GA, Almeida HJ, Gaião AA. Inventário de Depressão Infantil - CDI: estudo da adaptação com escolares de João Pessoa. J Bras Psiquiatr 1995; 44: 345-349.

31. Hallak LRL. Estimativa da prevalência de sintomas depressivos em escolares da rede pública de Ribeirão Preto. [Master's thesis]. Ribeirão Preto: Faculdade de Medicina de Ribeirão Preto da USP; 2001.
32. Cameron N. The methods of auxological anthropometry. In: Falkner F, Tanner JM (Editors), Human growth. A comprehensive treatise. Methodology: ecological, genetic, and nutritional effects on growth. Vol 3. 2nd edn. New York: Plenum Press; 1985. p 3-46.

33. The fourth report on the diagnosis, evaluation, and treatment of high blood pressure in children and adolescents. Pediatrics 2004; 114 : 555-576.

34. Asher MI, Keil U, Anderson HR, Beasley R, Crane J, Martinez F, et al. International Study of Asthma and Allergies in Childhood (ISAAC): rationale and methods. Eur Respir J 1995; 8: 483-491.

35. Paes-Sousa R. Intra-urban mortality differentials in Belo Horizonte, Minas Gerais State, Brazil, 1994: revisiting the debate on demographic and epidemiological transitions. Cad Saúde Pública 2002; 18: 1411-1421.

36. Barreto ML, Carmo E. Mudanças em padrões de morbi-mortalidade: Conceitos e métodos. In: Monteiro C (Editor), Velhos e novos males da saúde no Brasil: A evolução do país e suas doenças. São Paulo: Editora Hucitec/Núcleo de Pesquisas Epidemiológicas em Nutrição e Saúde, Universidade de São Paulo; 1995. 